\title{
A utilização da pesquisa-ação na administração: engajamento político ou intervenção prática?
}

\section{Use of research-action in administration: political engagement or practice intervention?}

\author{
Cleunice Zanella ${ }^{1}$
}

\section{Resumo}

\begin{abstract}
A pesquisa-ação quando aplicada aos estudos organizacionais pode ter dupla orientação: engajamento político ou intervenção prática. Este estudo objetiva analisar o enfoque de aplicação da pesquisa-ação nas pesquisas em Administração a partir das bases de dados e periódicos indexados a Capes. Foram selecionados 16 artigos nacionais e 7 internacionais que indicaram o uso desta abordagem metodológica no desenvolvimento das suas pesquisas. Os dados foram coletados a partir de uma pesquisa bibliográfica, com caráter descritivo e abordagem qualitativa. Os resultados mostram que, apesar de afirmarem ter usado a pesquisa-ação em seus estudos, em parte dos artigos analisados não é possível verificar a aplicação da pesquisa-ação. Há indícios ainda de que, de maneira geral, os autores não distinguem adequadamente suas intenções com o uso da pesquisa-ação e que há predominância do seu uso na busca por melhorias de processos organizacionais, a partir da busca por solução de problemas evidenciados pelas organizações.
\end{abstract}

Palavras-chave: Pesquisa-ação. Administração. Organizações.

\begin{abstract}
Action research is an argumentative research approach that, when applied to organizational studies, can have a dual orientation: political engagement, with a focus on improving the subjects' living conditions, or practical intervention, aimed at solving organizational problems through consultancies. This study aims to analyze the application of action research in Administration, in the national and international scenario, from the databases and periodicals indexed to Capes. We selected 16 national and 7 international papers that indicated the use of this methodological approach in the development of their research. The data were collected from a bibliographic research, with descriptive character and qualitative approach. The results show that, although they affirm that they have used action research in their studies, in part of the articles analyzed it is not possible to verify the application of action research. There are also indications that, in general, the authors do not adequately distinguish their intentions with the use of action research and that their use is predominant in the search for improvements of organizational processes, starting from the search for solution of problems evidenced by the organizations.
\end{abstract}

Keywords: Action research. Management. Organizations.

\footnotetext{
1 Doutoranda do programa de pós graduação em Administração pela Universidade Federal de Santa Catarina - UFSC. Docente do curso de Administração da Universidade Comunitária da Região de Chapecó - UNOCHAPEÓ. E-mail: cleunice@unochapeco. edu.br
} 


\section{Introdução}

A evolução da ciência administrativa pode ser considerada como uma evolução ou aperfeiçoamento do paradigma dominante, o positivismo, como bem apontado por Garcia e Bronzo (2000), para os quais existe uma continuidade histórica do pensamento da administração que se materializou nos padrões e formas de racionalidade nos últimos 100 anos, não havendo mudanças substantivas. O desenvolvimento das teorias organizacionais revela uma complexidade própria, pois refletem uma forma particular de observação dos fatos sociais na esfera da produção e do trabalho, carregada de valores e referências dominantes, com a subordinação da ciência aos movimentos mais amplos do capital e dos interesses dominantes (GARCIA; BRONZO, 2000).

Audet e Déry (1996) comentam sobre o discurso "cientifista", predominante no campo social no século XX. Enquanto Taylor e Fayol buscaram se sujeitar as leis empíricas, a Segunda Guerra Mundial impulsiona as ciências da administração, prestandose bem ao governo, coordenação e controle, criação da ordem (AUDET, DÉRY, 1996; GARCIA, BRONZO, 2000). A cientifização das práticas tornam explícitos os discursos epistemológicos que portam regras de produção e validação, projetando as ciências da administração uma imagem de ciência unitária. No entanto, já no final do século passado e início deste, verifica-se uma perspectiva de mudança com discussão do paradigma emergente, considerando que o conhecimento não é único, mas parcial, e que não pode ser externo ao sujeito.

Para Chevallier e Loschak (1982), a ciência administrativa não objetiva uma realidade pronta, necessita ser reconstruída à luz de uma problemática teórica específica, devendo superar os obstáculos epistemológicos (parasitismo ideológico, normativismo e as armadilhas do empirismo), podendo utilizar o patrimônio das ciências já constituídas, enriquecendo seus instrumentos conceituais e aperfeiçoando suas técnicas de investigação. Os autores consideram ainda que a administração não tem o papel de preparar e aplicar as decisões tomadas pelo poder do político, não sendo, portanto, um aparelho de gestão especializado, profissionalizado e hierarquizado. No entanto, mais do que outra ciência social, a administração corre o risco de ser colocada, mesmo que indiretamente, ao serviço do poder, canalizando a pesquisa através de um expediente particularmente eficaz: o dinheiro.

Nesta mesma direção, Garcia e Bronzo (2000) consideram que as instituições não podem ser reduzidas ao conhecimento de suas estruturas, relações de subordinação e normas, pois são lugares privilegiados para a luta política. Torna-se necessário aproximar as teorizações do campo da administração às ciências sociais correlatas, como a economia, política e sociologia, podendo, com isso, evitar que se torne uma ciência vazia, distante da realidade social e presa a antigas referências locais e formais de análise.

Corroborando com Garcia e Bronzo (2000), cita-se Chevallier e Loschak (1982), (1997), Audet e Déry (1996) e Serva (2001) para os quais há uma grande expectativa com uma "revolução científica" no campo das ciências sociais, consequentemente na administração. Para tanto, segundo esses autores, há necessidade de apoiar-se em outras áreas, como a antropologia, sociologia, economia.

Mesmo não sendo consenso, o paradigma dominante cede lugar a um paradigma emergente, reconhecendo a influência da subjetividade e o reconhecimento de que fatores históricos, sociais, econômicos e culturais influenciam a construção do conhecimento, como pode ser verificado nos trabalhos e pesquisas realizadas no campo das ciências sociais, mais especificamente no estudo da administração.

Segundo Novaes e Gil (2009), verifica-se uma ênfase cada vez maior no campo da administração em pesquisas de cunho interpretativista, nos quais a ênfase está não na procura da objetividade, mas na 
maneira como os sujeitos de pesquisa interpretam a realidade que vivenciam. Para os autores, tal fato pode ser constatado no Brasil a partir da análise dos anais dos últimos encontros da Associação Nacional de Pós-Graduação em Administração (EnANPAD). Os autores avaliaram os anais deste evento entre os anos de 2006 a 2008 e evidenciaram um crescente número de relatos de pesquisa elaborados sob as bases da fenomenologia, da etnografia, do interacionismo simbólico e da grounded theory, sendo possível também constatar a presença de relatos de pesquisa-ação.

Para Vergara (2005), enquanto os principais tipos de pesquisa quantitativa são survey, correlação, causal-comparativa e experimental, as principais formas de abordagem qualitativa são a pesquisaação, pesquisa histórica, estudo de caso, o focus group, etnografia e a grounded theory. De acordo com Neves (1996), os métodos de investigação se classificam como quantitativos e qualitativos por apresentarem características contrastantes quanto à forma e ênfase, entretanto não são excludentes. O pesquisador pode, ao desenvolver o seu estudo, utilizar os dois, usufruindo, por um lado, da vantagem de poder explicitar todos os passos da pesquisa e, por outro, da oportunidade de prevenir a interferência de sua subjetividade nas conclusões obtidas.

Entre as abordagens citadas, neste estudo interessa a pesquisa-ação, na qual além de o pesquisador participar ativamente da pesquisa, visa promover mudanças no ambiente pesquisado. Apesar de ser possível perceber pesquisas realizadas com base em um paradigma emergente, que considera e reconhece a influência da subjetividade, como evidenciado por Novaes e Gil (2009), a aplicação da pesquisa-ação não é comum no estudo da administração, apesar de ser utilizada com muita frequência no âmbito das ciências sociais aplicadas como educação, serviço social e saúde pública (NOVAES, GIL, 2009).

A pesquisa-ação contemporânea muito tem evoluído como uma extensão da pesquisa aplicada em contextos sociais práticos, nos quais os participantes assumem papeis anteriormente ocupados por pesquisadores sociais que se mantinham distantes de tais configurações. A pesquisa participativa e a ação colaborativa surgiram mais ou menos como formas de resistência às convencionais práticas de pesquisas que foram percebidas por determinados tipos de participantes que se mantinham distantes das preocupações e interesses locais. Não se trata apenas de um interesse político ou histórico, mas desafia ainda alguns pressupostos sobre a natureza de pesquisa como prática social, além das "guerras de paradigmas" que tem atormentado a pesquisa social em grande parte do século passado (KEMMIS; MCTAGGART, 2000).

Para Kemmis e Mctaggart (2000), a pesquisaação tem como objetivo pôr em marcha processos pelos quais os participantes coletivamente fazem análises críticas sobre a natureza de suas práticas, seus entendimentos e contextos em que eles praticam, a fim de enfrentar e superar a irracionalidade, injustiça, alienação e sofrimento nesses cenários de prática e em relação às consequências de suas práticas nessas configurações. Segundo Creswell (2007), as comunidades tipificadas como exemplos de pesquisa participante são as vítimas de algum tipo de preconceito social (pessoas especiais, renda, titulação), racial (brancos, negros, asiáticos, índios), sexual (mulheres, homossexuais, bissexuais, transexuais).

Para Menelau, Santos e Castro (2011), a pesquisa-ação apresenta-se como uma alternativa viável à reaproximação da pesquisa acadêmica com a sociedade, visto que a intervenção na realidade e a busca pela transformação de pessoas e ambientes são questões centrais do seu arcabouço teórico. Deve-se salientar, no entanto, que de acordo com Thiollent (2003), a pesquisa-ação é um método de pesquisa qualitativa voltada à descrição de situações concretas de coletividade e a intervenção dos sujeitos é orientada em função da deliberação de problemas ou de objetivos de transformações. 
Nesse sentido Thiollent (2003, p. 83) analisa de forma crítica a utilização da pesquisa-ação na administração, argumentando que a PA foi distorcida por uma realidade presente na Administração, aplicada aos interesses particulares em detrimentos dos proveitos dos pesquisadores, afirmando que "quase nenhuma pesquisa e nenhuma ação podem ser realizadas sem o acordo e o consentimento dos empresários".

No entanto, para Park (1999), no contexto organizacional, a motivação para pesquisa baseada em ação decorre da necessidade de melhorar o funcionamento da empresa, com a finalidade de assegurar a sua sobrevivência ou sua rentabilidade. Martins (2006, p.47-48) vê a pesquisa-ação, no âmbito das organizações, como "uma proposta de pesquisa mais aberta, com características de diagnóstico e consultoria para clarear uma situação complexa e encaminhar possíveis ações, especialmente em situações insatisfatórias ou de crise".

Salienta-se ainda que, segundo De Sordi e Meireles (2010, p. 3), "nas últimas duas décadas ocorreu crescimento significativo de pesquisas que adotaram a estratégia pesquisa-ação, observou-se, também, o uso desta estratégia de forma confusa e até mesmo incorreta". De acordo com Tripp (2005, p. 447), o termo pesquisa-ação "vem sendo aplicado de maneira tão ampla e vaga que está se tornando sem sentido".

Além disso, para De Sordi e Meireles (2010), verifica-se uma preocupação muito grande com o uso indevido entre os especialistas em metodologia da pesquisa científica com relação aos termos estudo de caso, pesquisa-ação e pesquisa participante. A confusão ocorre por várias razões, entre elas: (a) há muitas características comuns entre essas abordagens e alguns sutis aspectos diferenciais; (b) todas são abordagens recentes, comparadas com as mais tradicionais, como as relacionadas à alegação de conhecimento positivista; (c) há muitos autores sobre metodologia que as tratam como sinônimos.
Considerando as diferentes aplicações e objetivos da pesquisa-ação aplicada às ciências sociais, especialmente à administração, este estudo objetiva avaliar a aplicação da pesquisa-ação na administração no contexto nacional e internacional, a partir de uma pesquisa nos periódicos Capes, visando identificar se as pesquisas realizadas estão baseadas no engajamento político, conforme evidenciado por Thiollent (2003) e Creswell (2007), ou se estão baseadas na intervenção prática, por meio de consultorias, com intuito de implantar/melhorar programas e processos, como sugere Park (1999), além de avaliar se a pesquisa realizada, identificada como pesquisa-ação pode ser assim classificada, a partir do estudo das análises e resultados das pesquisas selecionadas.

\section{Revisão Teórica}

A pesquisa na Administração: os paradigmas orientadores

O estudo da administração é fortemente influenciado por paradigmas, que orientam os procedimentos metodológicos utilizados para o desenvolvimento de pesquisas nesta área. Um dos modelos adotados para descrever os paradigmas (ou visões de mundo) da administração é o apresentado por Burrell e Morgan (1979), que considera os pressupostos acerca da natureza das ciências sociais e da sociedade.

Burrell e Morgan (1979) apresentam os pressupostos sobre a natureza da ciência social, considerando que é conveniente conceituar ciência social em termos de quatro conjuntos de pressupostos relativos a: a) ontologia (verdadeira essência do fenômeno sob investigação), b) epistemologia (bases do conhecimento - como alguém poderia começar a entender o mundo e transmitir esse conhecimento para seus semelhantes em forma de comunicação; determinam questões extremas como: o conhecimento pode ser algo adquirido ou somente experimentado pessoalmente?), c) natureza humana 
(a relação ente seres humanos e seu ambiente) e d) metodologia (como se tenta estudar e obter conhecimento no mundo social), pois, segundo os autores, todos os cientistas sociais abordam seus temas por meio de pressupostos implícitos ou explícitos acerca da natureza do mundo social e da maneira como ele pode ser investigado.

Os autores apresentam então o que denominam "fios do debate", caracterizando: a) debate ontológico: nominalistmo e realismo; b) debate epistemológico: positivismo e antipositivismo; c) debate sobre a natureza humana: voluntarismo e determinismo; e d) debate metodológico: teoria ideográfica e nomotética. Tais conjuntos de pressupostos apresentam uma poderosa ferramenta para análise organizacional:

- Funcionalista (realista, positivista, determinista e nomotético): voltado para explanações essencialmente racionais de assuntos sociais.

- Interpretativo (nominalista, antipositivista, voluntarista e ideográfico): busca a explanação dentro o reúno da consciência individual e da subjetividade.

- Humanismo radical (nominalista, antipositivista, voluntarista e ideográfica): ênfase na consciência humana; a consciência do homem é dominada pelas superestruturas ideológicas com as quais ele interage.

- Estruturalismo radical (realista, positivista, determinista e nomotético): advogam a sociologia da mudança radical sob o ponto de vista objetivista.

Para Burrell e Morgan (1979) dentre os quatro paradigmas sociológicos, o funcionalismo constitui até então a ortodoxia em estudos organizacionais. Neste sentido, segundo Caldas e Fachin (2005) e Vergara e Caldas (2005) de 1980 até o momento (2005), o campo nos estudos organizacionais cresceu exponencialmente e abraçou especialmente a ortodoxia funcionalista, apesar do crescimento de vertentes interpretacionistas, críticas e, mais recentemente, pós-modernas.

De acordo com Caldas e Fachin, (2005) pelo menos quatro debates emergiram fortemente no campo, gerando tradições teóricas concorrentes que expandiram a tradição funcionalista e povoaram suas publicações nos últimos vinte e cinco anos, sendo: 1) de natureza intrinsecamente determinista, entre perspectiva de adaptação e de seleção; 2) entre perspectivas determinísticas e voluntaristas; 3 ) entre ação individual e ação coletiva; 4) entre modelos racionais e modelos normativo-institucionais, que chama de "organizações" versus "instituições".

Segundo Vergara e Caldas (2005), enquanto para o interpretacionista as organizações são processos que surgem das ações intencionais das pessoas, individualmente ou em harmonia com outras sendo uma rede de representações completas e subjetivas, para o funcionalista as organizações são objetos tangíveis, concretos e objetivos. No paradigma interpretacionista, tenta-se compreender e explicar o mundo social a partir do ponto de vista das pessoas envolvidas nos processos sociais. Os pressupostos do paradigma interpretacionista estão presentes em trabalhos de pesquisadores de estudos organizacionais no Brasil. Mesmo incipiente, já mostra grande riqueza, possibilitando significativo potencial de contribuição à área de estudos organizacionais no país.

No estudo de Burrell e Morgan (1979), o interpretacionismo diz respeito a uma abordagem subjetivista da ontologia, da epistemologia, da natureza humana e da metodologia. Esses pensadores, que tanto auxiliaram com seu mapeamento, contribuíram também para uma visão exclusivista de cada paradigma por eles identificado, considerando-os mutuamente excludentes. Essa visão gerou críticas, desencadeando pesquisas reativas, que buscam superar a dicotomia apontada. Posteriormente Morgan e Smircich (1980) tentam minimizar essa dicotomia, sugerindo fronteiras mais permeáveis e a possibilidade de muitas matizes 
entre as inclinações subjetivistas e objetivistas.

Devido a forte influência dos paradigmas no posicionamento do pesquisador, conforme evidenciado por Novaes e Gil (2009), a discussão sobre os aspectos epistemológicos é de extrema relevância para a realização de pesquisas em ciências sociais. Kemmis e McTaggart (2000) comentam que tais aspectos se concentram nas dicotomias que dividiram as abordagens das ciências humanas e sociais: a) dicotomia entre individual e grupal; b) dicotomia entre objetivo e subjetivo.

Kemmin e McTaggart (2000) admitem que em ambos os casos sejam falsas dicotomias, ou seja, são ambos os aspectos constitutivos um do outro. A partir disso, comentam sobre a prática reflexiva, sob um ponto de vista dialético. Desafiam as dicotomias ou dualismos que separam os quatro primeiros pontos de vista de um do outro: os dualismos do indivíduo contra o social e o objetivo em relação ao subjetivo. Tentam mostrar que cada uma dessas dimensões não são opostas, mas em termos de reciprocidade e relação entre estes diferentes aspectos. Desta forma, se tem o individual e o social, o objetivo e o subjetivo, como aspectos relacionados com a vida e prática humana, para ser compreendido dialeticamente.

Neste ponto de vista, é necessário entender a prática como promulgada por indivíduos que atuam no contexto da história e de formas constituídas por uma vasta rede histórica de interações sociais entre as pessoas. Da mesma forma, é necessário entender a prática como tendo tanto aspectos subjetivos como objetivos, sendo ambos necessários para entender como qualquer prática é realmente exercida, como é constituída historicamente e socialmente e como pode ser transformada. Este ponto de vista da relação entre o objetivo e o subjetivo às vezes é também descrito como "reflexiva", porque alterar as condições objetivas muda a maneira em que uma situação é interpretativamente entendida, que por sua vez muda a forma como as pessoas agem sobre o "externo" e significa que o que eles fazem é entendido e interpretado de maneira diferente, e que os outros também agem de forma diferente, e assim por diante (KEMMIN; MCTAGGART, 2000).

Para Kemmin e McTaggart (2000), quanto às perspectivas metodológicas, verifica-se que diferentes pesquisadores enfatizam diferentes aspectos da prática em suas investigações, dependendo de métodos de pesquisa e técnicas que parecem mais apropriadas ao estudo, visualizadas a partir das perspectivas particulares que adotam. Diferentes perspectivas metodológicas na pesquisa sobre a prática estão relacionadas a diferentes perspectivas epistemológicas sobre a natureza da prática.

Estas observações têm implicações para o debate contemporâneo entre abordagem "quantitativa" e "qualitativa" na ciência social (KEMMIS; MCTAGGART, 2000) e tais implicações refletem na seleção, por parte do pesquisador, das estratégias e métodos de pesquisa e, neste sentido, deve-se certamente reconhecer que há uma pluralidade de perspectivas com relação aos métodos e técnicas de investigação.

A questão é se essa pluralidade pode ser entendida como o que sugere uma perspectiva de ordem superior em que é possível triangular estas perspectivas diferentes umas com outras para chegar a uma perspectiva mais multifacetada que, mesmo que não promete integridade, inteireza, ou um alto nível de unificação das perspectivas que se reúne, pelo menos, alerta como as diferentes perspectivas podem ser interligadas (KEMMIS; MCTAGGART, 2000).

Neste sentido, quanto à validade, a pesquisa não pode ser considerada como auto justificação, ou justificada unicamente com base em critérios internos, pois pesquisa também é uma prática social a ser avaliada em relação aos critérios como os objetivos da ação de investigação, tanto no ambiente de pesquisa e de modo mais geral, em termos de suas consequências mais amplas (KEMMIS; MCTAGGART, 2000). 
Finalmente em estudos organizacionais, seja com aceitação de que organizações são movimentos objetivos e subjetivos, seja realizando conversações entre os paradigmas delineados por Burrell e Morgan (1979) ou utilizando, complementarmente, métodos quantitativos e qualitativos de pesquisa na captação da realidade, têm-se feito esforços na direção da superação da dicotomia objetivismo/subjetivismo. Vê-se interpretacionistas e funcionalistas juntaremse a outros no processo de fazer ciência. O fato é que a realidade social, grupal, individual transborda da capacidade do pesquisador dela dar conta.

\section{Pesquisa-ação (PA) como modalidade de pesquisa}

De acordo com Thiollent (1985, p. 14), a pesquisa-ação é definida como uma pesquisa com base empírica, e visa "alcançar realizações, ações efetivas, transformações ou mudanças no campo social”. Para o autor, a PA é um método de pesquisa social realizado "em estreita associação com uma ação ou com a resolução de um problema coletivo e no qual os pesquisadores e os participantes representativos da situação ou do problema estão envolvidos de modo cooperativo ou participativo". Neste mesmo sentido para Barbier (2007, p. 14) "a pesquisa-ação obriga o pesquisador de implicar-se [...] não se trabalha sobre os outros, mas é sempre com os outros". A partir dessas afirmações, verificase a necessidade de engajamento salientada por Barbier (2007) que também é evidenciada por Thiollent (2003, p. 15) ao afirmar que "Para que não haja ambiguidade, uma pesquisa pode ser qualificada de pesquisa-ação quando houver realmente uma ação por parte das pessoas ou grupos implicados no problema sob observação".

Quanto ao processo de coleta de dados na PA, tanto Thiollent (2003) como Barbier (2007) consideram que qualquer técnica pode ser utilizada, desde que contribua para a resolução do problema. Da mesma forma Stringer (1996) afirma que o processo de coleta de dados pode ser tanto por meio de técnicas qualitativas, quanto quantitativas.
Barbier (2007, p. 143-144) apresenta orientadores para a realização da PA: "situação problemática; planejamento e ação $\mathrm{n}^{0} 1$; avaliação e teorização; retroação sobre o problema; planejamento e ação $\mathrm{n}^{\mathrm{o}} 2$; avaliação e teorização; retroação sobre o problema; planejamento e ação $\mathrm{n}^{0} 3$; avaliação e teorização; e assim sucessivamente."

Para Tripp (2005, p. 447), "pesquisa-ação é uma forma de investigação-ação que utiliza técnicas de pesquisa consagradas para informar a ação que se decide tomar para melhorar a prática". O autor acrescenta ainda "que as técnicas de pesquisa devem atender aos critérios comuns a outros tipos de pesquisa acadêmica (isto é, enfrentar a revisão pelos pares quanto a procedimentos, significância, originalidade, validade etc.)".

Apesar de haver semelhanças entre a pesquisa participante e a pesquisa-ação, como a interação entre os pesquisadores e pesquisados ou pessoas envolvidas nas situações investigadas, de acordo com Novaes e Gil (2009), há grande diferença entre ambas no que se refere ao caráter emancipatório da pesquisa participante. Neste sentido, enquanto a pesquisa-ação que pode ser de caráter social, educativo, técnico ou outro, a pesquisa participante tem como propósito fundamental a emancipação das pessoas ou das comunidades que a realizam.

Segundo Novaes e Gil (2009), a origem das duas modalidades podem explicar essas diferenças. Apesar de autores como Tripp (2005) afirmarem que não existe muita certeza sobre quem inventou a pesquisa-ação, para Novaes e Gil (2009) esta modalidade surgiu nos Estados Unidos no período seguinte à Segunda Guerra (LEWIN, 1970) enquanto a pesquisa participante surgiu na América Latina, visando promover grupos tidos como marginalizados (BRANDÃO; STECK, 1999; SILVA, 1991).

Ainda com relação às diferenças entre a pesquisa participante e pesquisa-ação, destaca-se que a primeira caracteriza-se como um modo de observação em que o pesquisador se identifica com 
o grupo pesquisado, objetivando compreender o problema a partir da perspectiva do sujeito ou grupo e, neste caso, somente o pesquisador participa do processo de investigação, que não envolve necessariamente o sujeito. Já a pesquisa-ação possui um caráter participativo, pois promove interação entre pesquisador e membros representativos da situação investigada. Neste sentido, uma das principais diferenças está no fato de que a pesquisa participante induz a discussões entre pesquisador e membros da situação investigada, mas não implica uma ação planejada, enquanto a pesquisa-ação é centrada na intervenção planejada dos sujeitos em uma dada realidade (THIOLLENT, 1997; VERGARA, 2005).

A pesquisa-ação objetiva, simultaneamente, intervenção, elaboração de conhecimento e seu desenvolvimento (VERGARA, 2005). Já a pesquisa participante pode ser definida como uma modalidade de pesquisa que tem como propósito "auxiliar a população envolvida a identificar por si mesma os seus problemas, a realizar a análise crítica destes e a buscar as soluções adequadas" (LE BOTERF, 1984, p. 52), na qual a população não é considerada passiva e o planejamento e condução da pesquisa não ficam a cargo de pesquisadores profissionais, assim como a seleção dos problemas, que emergem da população envolvida. Já a pesquisa-ação, segundo Novaes e Gil (2009), tem características situacionais, pois procura diagnosticar um problema específico em uma situação específica, visando alcançar algum resultado prático àquela situação.

Park (1999) praticamente descarta a possibilidade de ocorrência da pesquisa participante no contexto das organizações, pois sua realização é motivada pelas necessidades de uma comunidade, visando a melhoria das condições de vida das pessoas.

Para evidenciar a pesquisa-ação, é possível considerar algumas de suas características, conforme citado por De Sordi e Meireles (2010), como: a pesquisa em desenvolvimento deve trazer ação e almejar transformação do ambiente pesquisado; os pesquisadores estão envoltos, trazem o processo de mudança para entidade pesquisada, agindo no ambiente organizacional, seja como consultores, funcionários, colaboradores, fornecedores ou clientes.

A descrição da ação dos pesquisadores no ambiente pesquisado, no contexto da pesquisa-ação, é evidenciada por Thiollent $(1985,2003)$ ao afirmar a importância do envolvimento dos sujeitos na ação. Neste sentido, todos envolvidos na execução da pesquisa, além dos pesquisadores, devem ter atitude participativa ou cooperativa e esse envolvimento é motivado em função da escolha de um tema que seja de interesse comum e representativo de uma situação ou de um problema interessante a todos (DE SORDI, MEIRELES, 2010).

Por fim, para De Sordi e Meireles (2010), é possível indicar pelo menos três características básicas da pesquisa-ação: a) ter a comunidade envolvida com a pesquisa; b) existir pertinência da situação ou problema de pesquisa com a comunidade; c) existência de trabalho cooperativo entre pesquisadores e comunidade.

\section{Pesquisa-ação e sua aplicação na Administração}

De acordo com Vergara e Peci (2003), a lógica positivista é predominante em pesquisas na área de Administração, tanto no cenário nacional como internacional. Podendo ser considerada como um método de pesquisa qualitativa, ministrado aos campos de pesquisa relacionados às formas de ação coletiva, a pesquisa-ação pode possibilitar a descrição de situações concretas de coletividade e à intervenção dos sujeitos, orientada em função da deliberação de problemas ou de objetivos de transformação, conforme evidenciado por Thiollent (2003), podendo gerar uma inovação epistemológica nos métodos aplicados as pesquisas na Administração, pois a pesquisa-ação se posiciona como uma corrente de princípios metodológicos de natureza argumentativa, na qual há interações entre pesquisador e pesquisado, opondo-se a ideia de não 
interferência das técnicas tradicionais (BARBIER, 2007; THIOLLENT, 2003), suportadas pelo paradigma dominante.

De acordo com Menelau, Santos e Castro (2011), entre os métodos que permeiam a pesquisa qualitativa aplicada à Administração, a pesquisaação é a que mais se aproxima de uma postura decididamente comprometida com a produção de impactos significativos à realidade estudada, despontando como uma alternativa viável para reaproximar a pesquisa acadêmica da sociedade, visto que a intervenção na realidade e a busca pela transformação de pessoas ou ambientes são umas das questões centrais do seu arcabouço teórico.

Segundo Greenwood e Levin (2006), o argumento da pesquisa-ação reside na condução da investigação em uma perspectiva co-produtiva com o outsider (indivíduo fora do contexto de pesquisa acadêmica), que reflete uma ação social válida para o sujeito, podendo empregar métodos múltiplos de investigação, de forma a selecionar as técnicas que melhor se adéquem aos argumentos necessários para o problema que se apresenta.

Quanto ao início da utilização da pesquisa-ação da área de Administração, de acordo com Tripp (2005), não há um consenso, havendo indícios de que nos Estados Unidos a pesquisa-ação tenha sido aplicada nesta área por volta de 1940, a partir dos trabalhos de Lewin (1970). Para Thiollent (1985) a pesquisa-ação segue sendo aplicada na Europa em meados de 1960. Gajardo (1986) assinala que na América Latina a pesquisa-ação foi sendo aplicada entre os anos de 1960 a 1970. De acordo com Thiollent (2003), trabalhos de pesquisa-ação aplicados às organizações aparecem nos anos de 1980.

Thiollent (1985, p. 82-83) critica a aplicação da pesquisa-ação da Administração:

Á área organizacional é muito mal vista por parte de muitos pesquisadores de outras áreas devido ao fato de que a organização é muito marcada pelo espírito empresarial [...]. Além disso, no mundo dos pesquisadores e dos consultores da área, há um clima de competição, segredo, 'arrivismo' [...] parecem sobretudo preocupados em 'faturarem', recorrendo inclusive a métodos 'participativos' sem efetiva contribuição.

Em estudo posterior, Thiollent (1997) comenta que a pesquisa-ação abre novos caminhos para a investigação social em diversos setores e, em particular, na área organizacional, pois como fonte de informação insubstituível, as intervenções nas organizações são oportunidades para os pesquisadores terem acesso a informações e problemas que com frequência não se encontram diretamente nos estudos e pesquisas tradicionais. Além disso, destaca o autor, nas organizações, a participação deve ser desenvolvida em um processo contínuo de aprendizagem, por meio de uma abordagem que enfatiza a co-aprendizagem, a participação coletiva e a transformação organizacional.

Identificam-se as seguintes fases da pesquisaação nas organizações: conscientização do indivíduo ou grupo, aprofundamento na pesquisa dos problemas da organização, proposta coletiva de ação, na busca de soluções ou mudanças, que são também objeto de investigação e avaliação. As sínteses finais e a experiência acumulada formam a base de um possível avanço no conhecimento prático das organizações (THIOLLENT, 1997).

Já para Martins (2006, p.47-48), no âmbito das organizações a pesquisa-ação pode ser vista como "uma proposta de pesquisa mais aberta, com características de diagnóstico e consultoria para clarear uma situação complexa e encaminhar possíveis ações, especialmente em situações insatisfatórias ou de crise".

Nesta mesma direção, para Park (1999) a motivação para realização de pesquisas baseadas em ação realizadas em organizações decorre da necessidade de melhorar o funcionamento da 
organização, visando assegurar a sua sobrevivência ou sua rentabilidade e, neste sentido, tais objetivos podem ser melhor satisfeitos por intermédio da melhoria das condições de trabalho das pessoas, sendo possível permitir à elas um grau de autonomia na maneira como eles farão seus trabalhos. Este é certamente o pressuposto subjacente a pensar em grande parte em pesquisa baseada em ação, centrada, praticada e escrita acerca de contextos organizacionais.

A partir das considerações de Thiollent (1985, 1997, 2003) Park (1999) e Martins (2006), verificam-se diferentes abordagens ao se tratar da pesquisa-ação aplicada ao contexto da Administração. Neste sentido, a pesquisa-ação pode apresentar dupla orientação nos estudos aplicados às organizações: comprometimento com pesquisa e produção de conhecimento e o engajamento na solução de problemas organizacionais (MCKAY; MARSHALL, 2007), com enfoque na consultoria.

Neste sentido, salienta-se que no caso do comprometimento com a pesquisa e produção do conhecimento, o que define o tema e o problema de pesquisa é o interesse do investigador, enquanto no caso da consultoria o problema de pesquisa refere-se a um problema organizacional para o qual se aplica a pesquisa-ação, visando resolvê-lo (MCKAY; MARSHALL, 2007).

Deve-se considerar ainda que, assim como qualquer outro método de pesquisa aplicado à Administração, a pesquisa-ação também pode expressar obliquidade em sua articulação, visto que não é dada a concepção de generalização, característica esta recorrente de alguns estudos que empregam o método qualitativo. Além disso, destaca-se como outro possível viés, o fato de que no plano de ação objetiva-se alinhar sincronicamente a tomada de consciência dos outsiders com as exigências técnicas e científicas, dentre as quais se destaca a publicação dos resultados. Além do mais, a escolha dos participantes para a investigação, a participação efetiva na ação, bem como a proposta de ação na realidade estudada também pode ser um viés e apresentar-se como uma situação que levanta controvérsias.

A partir deste cenário que avalia a pesquisaação e sua aplicação em pesquisas da área de Administração, este estudo visa analisar qual o papel que a pesquisa-ação assume nas pesquisas em Administração, no cenário nacional e internacional, a partir das bases de dados e periódicos indexados a Capes.

\section{Procedimentos Metodológicos}

Quanto aos objetivos, esta pesquisa caracterizase como descritiva, uma vez visa descrever as características do portfólio bibliográfico selecionado. Para Merrian (1998) e Hair Junior et al. (2005) a pesquisa descritiva apresenta, basicamente, as características de uma situação, objetivando descobrir a associação entre variáveis.

Quanto à abordagem do problema, trata-se de uma pesquisa qualitativa, pois se pretendeu compreender como a pesquisa-ação tem sido aplicada no estudo da administração, a partir da análise de artigos publicados em periódicos.

Os dados utilizados neste estudo são do tipo secundário, obtidos a partir da coleta de artigos científicos publicados em periódicos, caracterizandose ainda como pesquisa bibliográfica, que para Oliveira (2007), é uma modalidade de estudo e análise de fontes científicas que remete para as contribuições de diferentes autores sobre o tema.

Para a coleta de dados, utilizou-se o portal Capes, disponível nas bases de dados restritas da Biblioteca Universitária da Universidade Federal de Santa Catariana (UFSC). Dentre as bases de dados indexadas a Capes, cita-se SPELL, SciELLO, ScienceDirect, Emerald Insight, SpringerLink, SAGE Journals, Wiley Online Library, entre outras.

O critério utilizado para a seleção dos artigos foi baseado na ocorrência dos descritores: 
"pesquisa-ação", "pesquisa-ação participante", "action research" relacionadas a "administração", "organizações", "management", "organizations".

Foram identificados 74 artigos nacionais e 104 internacionais, totalizando 178 artigos. Posteriormente foram avaliados os títulos e resumos dos artigos, visando selecionar somente aqueles que indicaram utilizar a pesquisa-ação no estudo da administração, compreendendo 48 artigos. Foram selecionados somente artigos teóricos-empíricos, pois busca-se analisar a aplicação desta abordagem, sendo descartado os artigos somente teóricos e os artigos repetidos. A partir deste filtro, o corpus da pesquisa foi composto por 16 artigos nacionais e 7 internacionais. A partir desta seleção, foi realizada leitura dos 23 artigos, identificados no quadro 1, visando verificar como a pesquisa-ação foi aplicada e com quais objetivos. Não houve corte temporal.

Quadro 1 - Artigos que compuseram o corpus da pesquisa

\begin{tabular}{|c|c|c|c|c|}
\hline Ordem & Autor(es) & Título do artigo & Periódico & Ano \\
\hline \multicolumn{5}{|c|}{ Artigos nacionais } \\
\hline 1 & Faria e Borinelli & $\begin{array}{c}\text { Análises multidimensionais e o conceito do custo } \\
\text { para servir em empresas de serviços logísticos: } \\
\text { uma pesquisa-ação }\end{array}$ & $\begin{array}{l}\text { RCO - Revista de } \\
\text { Contabilidade e } \\
\text { Organizações }\end{array}$ & 2010 \\
\hline 2 & $\begin{array}{l}\text { Lourenço Junior, } \\
\text { Oliveira e } \\
\text { Kilimnik }\end{array}$ & O planejamento de cenários como aprendizado & $\begin{array}{c}\text { Future Studies } \\
\text { Research Journal: } \\
\text { Trends and } \\
\text { Strategies }\end{array}$ & 2010 \\
\hline 3 & $\begin{array}{l}\text { Cruz Junior, } \\
\text { Carvalho e } \\
\text { Laurindo }\end{array}$ & $\begin{array}{l}\text { Estratégia e estrutura: em busca do alinhamento } \\
\text { organizacional em um clube social esportivo }\end{array}$ & $\begin{array}{l}\text { Gestão \& } \\
\text { Produção }\end{array}$ & 2005 \\
\hline 4 & $\begin{array}{l}\text { Bitencourt e } \\
\text { Garcez }\end{array}$ & $\begin{array}{c}\text { A influência da gestão de projetos na qualidade } \\
\text { de serviços prestados no caixa: um projeto } \\
\text { desenvolvido em uma empresa varejista }\end{array}$ & $\begin{array}{l}\text { Revista de Gestão } \\
\text { e Projetos }\end{array}$ & 2013 \\
\hline 5 & Cintra et al. & $\begin{array}{c}\text { A informação do setor de faturamento como } \\
\text { suporte a tomada de decisão: um estudo de caso } \\
\text { no hospital universitário da UFGD }\end{array}$ & $\begin{array}{l}\text { Ciência \& Saúde } \\
\text { Coletiva }\end{array}$ & 2013 \\
\hline 6 & Silva et al. & $\begin{array}{l}\text { Aspectos ergonômicos no planejamento e } \\
\text { execução de projetos: estudo de caso de um } \\
\text { centro de distribuição de produtos têxteis }\end{array}$ & $\begin{array}{l}\text { Revista de Gestão } \\
\text { e Projetos }\end{array}$ & 2012 \\
\hline 7 & $\begin{array}{l}\text { Pimentel, Carrieri } \\
\text { e Silva }\end{array}$ & $\begin{array}{c}\text { Posicionamento logístico com base nas estratégias } \\
\text { de produção em micro-organizações familiares: } \\
\text { um estudo de caso no setor têxtil }\end{array}$ & $\begin{array}{l}\text { Revista de } \\
\text { Ciências da } \\
\text { Administração }\end{array}$ & 2009 \\
\hline
\end{tabular}

Semina: Ciências Sociais e Humanas, Londrina, v. 38, n. 1, p. 93-116, jan./jun. 2017 


\begin{tabular}{|c|c|c|c|c|}
\hline 8 & Oliva et al. & $\begin{array}{l}\text { Desenvolvimento Sustentável: análise das } \\
\text { relações interorganizacionais na indústria de } \\
\text { celulose e papel }\end{array}$ & $\begin{array}{l}\text { Ambiente \& } \\
\text { Sociedade }\end{array}$ & 2012 \\
\hline 9 & $\begin{array}{l}\text { Pereira, Borchardt } \\
\text { e Geiger }\end{array}$ & $\begin{array}{l}\text { Uma nova abordagem para o marketing industrial } \\
\text { das PMEs: resultados de uma pesquisa- ação }\end{array}$ & Produção & 2008 \\
\hline 10 & Munck e Munck & $\begin{array}{l}\text { Gestão organizacional sob a logica da } \\
\text { competência: aplicação na pequena empresa }\end{array}$ & $\begin{array}{l}\text { RAM - Revista } \\
\text { de Administração } \\
\text { Mackenzie }\end{array}$ & 2008 \\
\hline 11 & Tamborlin et al. & $\begin{array}{l}\text { A capacidade de produção como recurso gerador } \\
\text { de ganhos }\end{array}$ & $\begin{array}{l}\text { Revista Eletrônica } \\
\text { de Estratégia e } \\
\text { Negócios }\end{array}$ & 2013 \\
\hline 12 & Cauchick Miguel & $\begin{array}{c}\text { QFD no desenvolvimento de novos produtos: um } \\
\text { estudo sobre a sua introdução em uma empresa } \\
\text { adotando a pesquisa-ação como abordagem } \\
\text { metodológica }\end{array}$ & Produção & 2009 \\
\hline 13 & $\begin{array}{l}\text { Pereira e } \\
\text { Bianchini }\end{array}$ & $\begin{array}{c}\text { Aplicação do método AHP na tomada de decisão } \\
\text { para a redução dos níveis de ação legal em } \\
\text { telecomunicações }\end{array}$ & $\begin{array}{l}\text { REMark. Revista } \\
\text { Brasileira de } \\
\text { Marketing }\end{array}$ & 2013 \\
\hline 14 & $\begin{array}{l}\text { Protil, Fernandes } \\
\text { e Souza }\end{array}$ & $\begin{array}{c}\text { Avaliação da pesquisa agropecuária em } \\
\text { cooperativas agroindustriais utilizando um } \\
\text { modelo de scorecard dinâmico }\end{array}$ & $\begin{array}{l}\text { RCO - Revista de } \\
\text { Contabilidade e } \\
\text { Organizações }\end{array}$ & 2009 \\
\hline 15 & Oliveira e Leone & $\begin{array}{l}\text { Gestão estratégica de benefícios: proposição de } \\
\text { um modelo matemático para assistência medica } \\
\text { dos funcionários }\end{array}$ & $\begin{array}{l}\text { RAM - Revista } \\
\text { de Administração } \\
\text { Mackenzie }\end{array}$ & 2008 \\
\hline 16 & $\begin{array}{l}\text { Vargas Neto e } \\
\text { Patah }\end{array}$ & $\begin{array}{c}\text { Planejamento de projetos em uma empresa } \\
\text { de consultoria de segurança patrimonial: uma } \\
\text { pesquisa-ação do desempenho de equipe de } \\
\text { projeto }\end{array}$ & $\begin{array}{l}\text { Revista de Gestão } \\
\text { e Projetos - GeP }\end{array}$ & 2013 \\
\hline \multicolumn{5}{|c|}{ Artigos internacionais } \\
\hline 1 & $\begin{array}{l}\text { Brunswicker e } \\
\text { Hutschek }\end{array}$ & $\begin{array}{l}\text { Crossing horizons: Leveraging cross-industry } \\
\text { innovation search in the front-end of the } \\
\text { innovation process }\end{array}$ & $\begin{array}{l}\text { International } \\
\text { Journal of } \\
\text { Innovation } \\
\text { Management }\end{array}$ & 2010 \\
\hline 2 & Carberry et al. & $\begin{array}{l}\text { The FARMSCAPE approach to decision support: } \\
\text { farmers', advisers', researchers' monitoring, } \\
\text { simulation, communication and performance } \\
\text { evaluation }\end{array}$ & $\begin{array}{l}\text { Agricultural } \\
\text { Systems }\end{array}$ & 2002 \\
\hline
\end{tabular}


A utilização da pesquisa-ação na administração: engajamento político ou intervenção prática?

\begin{tabular}{|c|c|c|c|c|}
\hline 3 & Chantarasombat & $\begin{array}{l}\text { Developing a Community Enterprise Consultant } \\
\text { Network for Isan }\end{array}$ & $\begin{array}{l}\text { Journal of Social } \\
\text { Sciences }\end{array}$ & 2011 \\
\hline 4 & $\begin{array}{l}\text { Cuéllar-Padilla e } \\
\text { Calle-Collado }\end{array}$ & $\begin{array}{l}\text { Can we find solutions with people? Participatory } \\
\text { action research with small organic producers in } \\
\text { Andalusia }\end{array}$ & $\begin{array}{l}\text { Journal of Rural } \\
\text { Studies }\end{array}$ & 2011 \\
\hline 5 & Greiner et al. & $\begin{array}{l}\text { Scenario modelling to support industry strategic } \\
\text { planning and decision making }\end{array}$ & $\begin{array}{l}\text { Environmental } \\
\text { Modelling \& } \\
\text { Software }\end{array}$ & 2014 \\
\hline 6 & $\begin{array}{l}\text { Hacklin e } \\
\text { Wallnofer }\end{array}$ & $\begin{array}{l}\text { The business model in the practice of strategic } \\
\text { decision making: insights from a case study }\end{array}$ & $\begin{array}{l}\text { Management } \\
\text { Decision }\end{array}$ & 2012 \\
\hline 7 & He et al. & $\begin{array}{l}\text { Integrative Management of Commercialized Wild } \\
\text { Mushroom: A Case Study of Thelephora ganbajun } \\
\text { in Yunnan, Southwest China }\end{array}$ & $\begin{array}{l}\text { Environmental } \\
\text { Management }\end{array}$ & 2011 \\
\hline
\end{tabular}

Fonte: Dados da pesquisa

Salienta-se que, para os textos escritos em outras línguas, foram realizadas traduções livres por parte dos autores. Para proceder à análise dos artigos, definiu-se um quadro de referências, baseado nos pressupostos básicos da pesquisa-ação, evidenciados por Thiollent (1985, 1997, 2003) McKay e Marshall (2007) e Barbier (2007), visando verificar se é possível evidenciar o uso da pesquisaação nos artigos selecionados, além de analisar o objetivo de sua utilização: engajamento político, para melhoria das condições de vida dos sujeitos, ou intervenção prática, focada em consultoria, visando resolução de problemas organizacionais.

Quadro 2 - Quadro de referência para análise dos artigos (princípios norteadores)

\begin{tabular}{|l|}
\hline Quais as temáticas estudadas? \\
\hline Qual o tipo de organização? \\
\hline Qual(is) o(s) objetivo(s) da pesquisa? \\
\hline Qual(is) a(s) técnica(s) de coleta de dados? \\
\hline O papel do pesquisador está claramente definido? \\
\hline É possível evidenciar a participação ativa dos sujeitos? \\
\hline Os sujeitos participam através de cooperação ou intervenção? \\
\hline Como se deu a escolha dos participantes? \\
\hline Qual a justificativa para o uso da pesquisa-ação? \\
\hline $\begin{array}{l}\text { Os resultados podem ser entendidos como mudança social, voltada ao atendimento do pesquisador ou intervenção } \\
\text { prática, voltada a resolução de um problema da organização, com características de consultoria? }\end{array}$ \\
\hline O objetivo da pesquisa parte do pesquisador ou de uma necessidade da organização? \\
\hline
\end{tabular}

Fonte: Dados da pesquisa 


\section{Resultados e Discussões}

Este capítulo apresenta os resultados obtidos por meio de pesquisa realizada referente a utilização da pesquisa-ação na administração, no cenário nacional e internacional, a partir dos periódicos Capes. Em primeiro lugar objetiva-se analisar se os estudos que afirmam ter usado a PA realmente o fizeram para, posteriormente, avaliar o enfoque de sua utilização na Administração, considerando os princípios norteadores indicados no quadro 2 .

Com relação às áreas da administração, notase que dos 16 artigos nacionais analisados o maior número estudou a temática do planeamento estratégico, totalizando cinco artigos. Dos demais, dois são aplicados na área de logística e o mesmo número foi encontrado na área de produção, projetos e gestão organizacional. Um artigo estudou logística e produção conjuntamente. Outras áreas foram estudas como administração pública, marketing e desenvolvimento de novos produtos, com um artigo em cada. Com relação aos artigos internacionais, há predominância na área de gestão estratégica, não ficando restritos a uma área específica, diferentemente do que foi observado nos artigos nacionais.

Ao avaliar o tipo de organização, nos artigos nacionais, verifica-se que a maioria dos estudos foi realizada em empresa privada, totalizando 13 artigos. Dos demais, dois trabalhos foram realizados na área pública e um em cooperativa. Não foram evidenciados, portanto, estudos no terceiro setor. No caso dos artigos internacionais, três foram realizados em empresas privadas, outros três com foco no desenvolvimento de atividades relacionadas a agricultura, mais especificamente com os produtores rurais, e um dos artigo foi desenvolvido na formação de consultores para atuar em pequenas empresas.

Visando identificar a finalidade dos estudos realizados, tomou-se como ponto de partida o enfoque do estudo, iniciando a análise pelo objetivo geral. Os resultados desta avaliação encontram-se no quadro 3.

Quadro 3 - Objetivos das pesquisas

\begin{tabular}{|c|l|}
\hline Ordem & \multicolumn{1}{c|}{ Objetivo da pesquisa } \\
\hline \multicolumn{2}{|c|}{ Artigos nacionais } \\
\hline 1 & $\begin{array}{l}\text { "Verificar, por meio de uma pesquisa-ação, as análises em nível multidimensional que podem ser } \\
\text { desenvolvidas em uma empresa de serviços logísticos, visando a otimizar a tomada de decisões dos } \\
\text { gestores, no que diz respeito aos objetos de análise filial, ponto de distribuição, rota e cliente" }\end{array}$ \\
\hline 2 & $\begin{array}{l}\text { "Objetiva-se propor um modelo de planejamento de cenários e avaliá-lo nas dimensões: processo } \\
\text { metodológico, resultados e comportamento. Busca-se demonstrar o potencial de um modelo experimental } \\
\text { de Planejamento de Cenários para mobilizar, motivar e agregar maior conteúdo à tomada de decisão } \\
\text { organizacional, principalmente no que se refere ao Planejamento Estratégico de duas instituições do } \\
\text { setor público: uma indústria farmacêutica e uma fundação de ensino tecnológico" }\end{array}$ \\
\hline 3 & $\begin{array}{l}\text { "Este artigo visa discutir o impacto da estrutura na formação de competências e implementação da } \\
\text { estratégia. Com o objetivo de investigar o processo de alinhamento entre estratégia e estrutura, a } \\
\text { abordagem metodológica adotada foi a pesquisa-ação" }\end{array}$ \\
\hline 4 & $\begin{array}{l}\text { "A questão de pesquisa foi: Como a gestão de projetos influencia a qualidade de serviços prestados } \\
\text { no caixa de forma a gerar impacto na satisfação dos clientes no mercado varejista? Como objetivo } \\
\text { secundário, avaliou-se a utilização formal dos processos de gerenciamento de projetos" }\end{array}$ \\
\hline
\end{tabular}




\begin{tabular}{|c|c|}
\hline 5 & $\begin{array}{l}\text { "O objetivo deste artigo é estruturar um modelo de relatório visando à utilização em hospitais } \\
\text { universitários, para a tomada de decisão" }\end{array}$ \\
\hline 6 & $\begin{array}{l}\text { "Objetivou-se antever riscos laborais na empresa, efetuando na fase de planejamento do projeto o uso } \\
\text { métodos e normas de ergonomia colaborativa e análise ergonômica do trabalho (AET), ou seja, o estudo } \\
\text { das atividades das operações in loco e com a participação efetiva dos operadores da empresa" }\end{array}$ \\
\hline 7 & $\begin{array}{l}\text { "Este artigo tem como objetivo descrever e analisar a estratégia de posicionamento logístico enfatizando } \\
\text { as decisões relativas às estratégias de produção e gestão de operações, em pequenas empresas familiares" }\end{array}$ \\
\hline 8 & $\begin{array}{l}\text { "A pesquisa desenvolvida procurou entender e analisar as relações dos agentes envolvidos na indústria } \\
\text { de celulose e papel" }\end{array}$ \\
\hline 9 & $\begin{array}{l}\text { "O presente trabalho apresenta os resultados de uma pesquisa-ação focada na criação de espaços de } \\
\text { prospecção para as PMEs junto aos fornecedores de primeiro e segundo nível da indústria automotiva" }\end{array}$ \\
\hline 10 & $\begin{array}{l}\text { "Este estudo objetiva explorar, descrever e mudar a sistemática de execução das atividades de uma } \\
\text { pequena empresa de consultoria" }\end{array}$ \\
\hline 11 & $\begin{array}{l}\text { "A pesquisa teve como objetivo identificar a capacidade de produção do setor de gravação de uma } \\
\text { clicheria da cidade de Blumenau/SC" }\end{array}$ \\
\hline 12 & $\begin{array}{l}\text { "Este trabalho objetiva apresentar a restruturação de um PDP e a implementação de um método de } \\
\text { suporte ao desenvolvimento de novos produtos, o desdobramento da função qualidade (QFD)" }\end{array}$ \\
\hline 13 & $\begin{array}{l}\text { "O objetivo desta pesquisa é desenvolver um roteiro para a implementação do alinhamento entre a } \\
\text { estratégia de negócios e a melhoria de processos de software em empresas desenvolvedoras de software" }\end{array}$ \\
\hline 14 & $\begin{array}{l}\text { "Desenvolver um instrumento de avaliação dos investimentos em pesquisa agrícola na cadeia produtiva } \\
\text { do trigo e seu impacto na rentabilidade de cooperativas agroindustriais." }\end{array}$ \\
\hline 15 & $\begin{array}{l}\text { "Apresentar um modelo para gestão estratégica de benefícios sociais, com base nos critérios de } \\
\text { acessibilidade e de redução de custos empresariais" }\end{array}$ \\
\hline 16 & $\begin{array}{l}\text { "O principal objetivo deste relato técnico é investigar como técnicas de planejamento de projetos podem } \\
\text { influenciar o desempenho das equipes" }\end{array}$ \\
\hline \multicolumn{2}{|r|}{ Artigos internacionais } \\
\hline 1 & $\begin{array}{l}\text { "Visa apresentar um método para realização de inovação aberta, unindo conceitos da psicologia } \\
\text { cognitiva e ação gerencial" }\end{array}$ \\
\hline 2 & $\begin{array}{l}\text { "Apresenta os resultados de um programa de gestão que teve como objetivo aplicar melhores práticas } \\
\text { de gestão para os agricultores do Nordeste da Austrália" }\end{array}$ \\
\hline
\end{tabular}




\begin{tabular}{|c|c|}
\hline 3 & $\begin{array}{l}\text { "Desenvolver uma rede de consultores para atuar em empresas comunitárias localizadas no nordeste da } \\
\text { Tailândia" }\end{array}$ \\
\hline 4 & "Promover um intercâmbio de conhecimentos entre os produtores, pesquisadores e consumidores" \\
\hline 5 & $\begin{array}{l}\text { "Este trabalho apresenta o resultado da aplicação de um modelo de simulação - Simulator (PPFs), cujo } \\
\text { objetivo é comunicar, negociar e integrar as perspectivas das partes interessadas, servindo como uma } \\
\text { ferramenta para "avaliação participativa integrada" }\end{array}$ \\
\hline 6 & $\begin{array}{l}\text { "Apresentar as implicações e limitações da aplicação da modelo de negócio como um dispositivo de } \\
\text { estratégias em uma empresa de alta tecnologia" }\end{array}$ \\
\hline 7 & $\begin{array}{l}\text { "O trabalho documenta um caso empírico de como uma abordagem interdisciplinar facilitou o } \\
\text { desenvolvimento de uma base científica para as políticas e práticas de gestão e construiu a capacidade } \\
\text { local para criar, adotar e manter novas regras e técnicas de gerenciamento" }\end{array}$ \\
\hline
\end{tabular}

Fonte: Dados da pesquisa.

Os artigos avaliados apresentaram o objetivo geral do estudo no resumo ou introdução, exceto o artigo 4 (nacional), que não apresenta claramente seu objetivo geral. Após identificação do objetivo dos estudos, buscou-se saber o design da pesquisa, bem como os instrumentos para coleta e análise de dados utilizados. Todos os 23 artigos avaliados tratam-se de estudos de caso, sendo que em quatro casos tem-se estudos de múltiplos casos, sendo o artigo 2 e 15 (nacionais) e 2 e 3 (internacionais).

Dentre as técnicas de coleta de dados destacam-se a pesquisa documental, entrevistas e questionários, reforçando a afirmação tanto Thiollent (2003) como Barbier (2007) ao considerarem que qualquer técnica pode ser utilizada, desde que contribua para a resolução do problema. Para Stringer (1996) o processo de coleta de dados pode ser tanto por meio de técnicas qualitativas, quanto quantitativas.

Os artigos 9 e 13 (nacionais) e 1, 5 e 7 (internacionais) não apresentam claramente os métodos para coleta de dados. Além de não descreverem, também não foi possível evidenciar com a leitura dos artigos quais técnicas para coleta de dados foram utilizadas. Destaca-se o artigo 12, que apresenta uma rica explicação quanto aos procedimentos metodológicos, descrevendo claramente como a pesquisa-ação foi aplicada.

Quanto à análise, dos 23 artigos, em 10 não foi possível evidenciar como foram analisados os dados. Quanto aos nacionais, nos artigos 5 e 7 os autores dizem ter realizado análise documental e análise de conteúdo, respectivamente. No artigo 10 os autores destacam que "a análise e interpretação dos dados se deram de forma exclusivamente qualitativa, envolvendo percepções subjetivas e objetivas dos autores e membros da organização sobre os itens exigidos pelos quadros [...]". No artigo 12 os autores destacam que realizaram "Interpretação de dados qualitativos; lógica indutiva; reflexões com base nas anotações do diário de pesquisa; dados de desenvolvimento de mais de 10 projetos analisados". Por fim, no artigo 15 os autores comentam ter realizado "análise de conteúdo, matemática e estatística", no entanto, afirmam tratar-se de um estudo qualitativo. Com relação aos artigos internacionais, dos 7, em 5 não está claro como os dados foram analisados. No artigo 4 os autores comentam ter realizado análise de conteúdo. No artigo 3 foi realizada análise de conteúdo, claramente descrita. 
A partir desta primeira análise dos artigos, que considerou aspectos metodológicos, realizase a análise da utilização da pesquisa-ação como estratégia ou método de pesquisa, visando identificar se nesses estudos pode-se afirmar que houve utilização da pesquisa-ação, considerando os princípios norteadores, apresentados no quadro 2.

Quanto ao papel do pesquisador, em 6 artigos, além de não descrever, não é possível evidenciar o papel e nem mesmo a participação na pesquisa. Nos artigos 1 e 9 apresenta-se como "consultor", sendo que neste último os autores escrevem que "A postura adotada pelos investigadores ao longo das etapas foi a de "consultores de processo". Em 3 artigos os pesquisadores podem ser identificados como "entrevistadores", mas nenhum dos artigos deixa claro qual papel exercem na pesquisa, da mesma forma que não está claro no artigo 2, podendo inferir que o pesquisador apresenta-se como "estimulador". Da mesma forma, nos 7 artigos internacionais, em 6 deles não é possível perceber claramente qual o papel do pesquisador. $\mathrm{O}$ artigo 2 apresenta como facilitador/consultor.

$\mathrm{O}$ artigo 12 novamente se destaca pela clareza da descrição ao afirmar que houve "atuação do pesquisador por meio da participação ativa em reuniões de projetos de desenvolvimento de novos produtos e observação não participativa de parte dos trabalhos de gestão de portfólio e de restruturação do processo de desenvolvimento de produtos. Esse acompanhamento proporcionou uma melhor interação entre as três iniciativas de implementação na empresa em estudo". No artigo 13 os autores descrevem que "a participação de um dos autores como pesquisador foi possível devido ao longo tempo de relacionamento com a empresa. A atuação se deu desde o planejamento preliminar da pesquisa até a finalização deste trabalho", mas não explica qual o papel assumido.

Com relação à participação ativa dos sujeitos, no caso dos artigos nacionais, novamente na grande maioria, ou seja, em 10 artigos, não foi possível evidenciar se participaram da pesquisa e muito menos "como". No artigo 2 os autores descrevem que os sujeitos "participaram das discussões da elaboração das etapas do modelo experimental". No artigo 4 os autores comentam que os sujeitos participaram na fase exploratória, mas não explicitam "como". No artigo 11, além de não deixar claro se participaram e como o fizeram, os autores descrevem que "com a finalidade de calcular o tempo padrão do setor de gravação, todos os funcionários foram 'comunicados' sobre a realização da pesquisa, sobretudo do viés acadêmico que ela propõe, bem como a proposta de otimizar o processo produtivo". Da mesma forma, no artigo 15 a participação não está clara e os autores afirmam apenas que "foram detectadas as principais expectativas dos funcionários, que basicamente eram duas: possibilidade de pagar a contrapartida financeira e inclusão dos dependentes no plano". Essa detecção pode ter se dado por meio de entrevistas, não exigindo a participação ativa dos sujeitos. Neste caso, pode-se inferir que os funcionários participaram como respondentes de questionamentos dos pesquisadores, diferentemente do que preconiza a PA, pois, de acordo com Thiollent (1985, 2003), deve haver o envolvimento dos sujeitos na ação e que todos envolvidos na execução da pesquisa, além dos pesquisadores, devem ter atitude participativa ou cooperativa (DE SORDI; MEIRELES, 2010).

Dentre os nacionais, destaca-se o artigo 12, no qual é possível evidenciar claramente a participação dos sujeitos quando os autores afirmam que "o nível de interatividade (com os envolvidos e com a organização), bem como a extensão (de tempo) pela qual essa interatividade ocorreu por meio da participação ativa em várias reuniões de projetos de desenvolvimento de novos produtos, sendo possível uma interatividade intensa com os envolvidos, de diferentes níveis hierárquicos e provenientes de diversas áreas funcionais da organização. Como referência, houve a participação em 93 reuniões de projeto em 42 dias em um ano". No artigo 16, 
apesar de os autores não deixarem claro, é possível perceber a participação dos sujeitos quando afirmam que "realizando discussões em grupo em torno dessa problemática, verificaram-se várias opiniões conflitantes, pois um dos gerentes acredita que esse indicador não tem importância, conforme depoimento do gerente A".

No caso dos artigos internacionais, dos 7 avaliados, em 5 é possível identificar a participação ativa dos sujeitos, tanto de forma colaborativa como na intervenção, exceto nos artigos 3 e 5 , nos quais tal participação não é identificada. Cita-se como exemplo os artigos 1 e 7. No primeiro, a participação se deu através de reuniões e discussões realizadas no "grupo de gestão da inovação", formado por especialistas em P\&D e marketing, além de um fornecedor alemão. No artigo 7 os autores citam que o estudo considerou questões empíricas visando reunir conhecimentos não apenas de cientistas e outros especialistas, mas também agricultores locais e funcionários florestais. Nesta colaboração, as diferentes partes interessadas trabalham em conjunto para identificar as causas e procurar a possível solução para o problema em questão.

Com relação à composição e escolha dos participantes de cada uma das pesquisas nacionais: no artigo 1 os autores descrevem que o grupo é formado por "pesquisadores, gestores e funcionária do setor de custos", mas não está claro como se deu a escolha dos membros. No artigo 2 os autores descrevem que "formaram grupos de discussão com perfis distintos para traçar cenários alternativos [...] Os funcionários foram divididos em grupos [...] as pessoas foram escolhidas para participarem de grupos cujos temas diferissem de sua área de atuação". O artigo 3 não explica como escolheu, apenas escreve "O grupo de trabalho no clube era constituído de todos os 12 gerentes, além de 10 supervisores e 9 coordenadores ligados aos gerentes. No que concerne aos diretores do clube, foram consultados 20 , dos quais 5 se envolveram mais ativamente no processo de redefinição da estrutura". O artigo 4 não evidencia, apenas diz que foi criado um time interdisciplinar. Nos artigos 5 a 8 não está claramente descrito e nem é possível perceber a partir da leitura dos trabalhos. O artigo 9 descreve que os participantes foram "indicados pela diretoria da federação [...] a etapa dos compradores teve início com a estruturação [...] nesta nova etapa foram introduzidos no 'comitê de mercado' empreendedores e gestores de vendas oriundos de PMEs que já participavam da rede de fornecedores das grandes empresas automotivas localizadas no estado. Esses profissionais, juntamente com os compradores da etapa anterior, formaram o grupo de trabalho desta etapa [...] o "comitê de mercado" pela diretoria da federação das indústrias e se caracterizou pela presença exclusiva de profissionais oriundos dos setores de compras das grandes organizações. A referida concentração advém da indicação dos nomes que foi feita pela diretoria da federação". O artigo 10 descreve que o grupo é formado pelos funcionários, mas não explica se são todos ou como se deu a escolha. Os artigos 11 e 14 nada comentam sobre a equipe. No artigo 12 os membros das equipes foram definidos de acordo com a área de atuação na empresa, mas não destaca qual o processo de seleção/escolha. $\mathrm{O}$ artigo 13 descreve que "a equipe definida para a condução e execução desta pesquisa foi composta por: um pesquisador; um diretor executivo e três coordenadores" descreve o perfil de ambos, mas não explica o processo de escolha dos membros. O artigo 15 afirma que todos os funcionários participaram, sendo 350 e 400 de cada empresa; mas comenta sobre um "grupo de funcionários" que, juntamente com os pesquisadores, receberam as propostas e discussões, mas não evidencia esse "grupo". Por fim, o artigo 16 apenas diz que foram 3 gerentes e 3 consultores que formaram a equipe.

Nos artigos internacionais, com relação à composição e escolha dos participantes, tem-se: no artigo 1 os autores comentam que o "grupo de gestão da inovação" foi formado por especialistas em P\&D e marketing, além de um fornecedor 
alemão, no entanto não justificam tal formação. No artigo 2 os autores citam que a pesquisa foi realizada com produtores de algodão e consultores, mas também não está claro como se deu a escolha. No artigo 4 participaram da pesquisa três produtores cujas áreas cultiváveis têm semelhança geográfica. No artigo 6 os autores comentam que estavam envolvidos na pesquisa oito membros da comissão, inclusive o presidente e diretor executivo, e as pessoas responsáveis pelo desenvolvimento de negócios, pesquisa e desenvolvimento, produção, vendas, marketing e finanças, mas também não justifica tal composição. No artigo 7 participaram da pesquisa pesquisadores, agricultores, indígenas e funcionários do governo. Nos artigos 3 e 5 não é possível evidenciar os participantes.

Avaliou-se ainda se os autores justificavam o uso da pesquisa-ação em seus trabalhos. Dos 16 artigos nacionais analisados, 5 não apresentam nenhuma justificativa para o uso da PA. O artigo 2 cita que "o método de pesquisa-ação foi utilizado em duas etapas deste estudo como um meio para a obtenção de informações relevantes sobre a aplicação prática do modelo experimental de planejamento de cenários", mas não diz claramente o porquê. No artigo 3 os autores comentam que "a estratégia de pesquisa adotada foi a pesquisa-ação, pois se pretendia estudar as questões citadas anteriormente, em tempo real, com a co-participação interativa dos pesquisadores, visando o propósito de desenvolver um entendimento holístico da situação em estudo"; neste caso os autores falam sobre a participação dos pesquisadores, mas não citam os sujeitos da pesquisa. Já no artigo 7, além da interação do pesquisador, cita-se a necessidade de interação dos pesquisados: "No presente estudo utiliza-se a pesquisa-ação de caráter instrumental, cujo foco pauta-se na resolução de problemas técnicos como, por exemplo, a solução de problemas dentro de uma organização. Objetiva-se, juntamente com os gestores da organização familiar, identificar, descrever e analisar o posicionamento logístico e as estratégias de produção e gestão de operações da empresa. Por sua vez, ela pode apontar possíveis soluções para o problema de posicionamento logístico de seus produtos".

Outros artigos justificam o uso da PA devido ao envolvimento dos participantes, como o artigo 11 "a pesquisa-ação está atrelada ao desenvolvimento de uma pesquisa, bem como ao planejamento de uma ação, e é caracterizada pelo envolvimento tanto dos pesquisadores quanto dos pesquisados no processo de pesquisa". No entanto, neste artigo, apesar de os autores afirmarem, não é possível evidenciar a participação ativa dos sujeitos. Isso ocorre ainda nos artigos 15 e 16. No entanto, no artigo 13 é possível evidenciar tal participação, além de afirmar que "a aplicação da abordagem de uma pesquisaação permitiu o refinamento gradativo do roteiro, o aprendizado dos participantes e a melhoria da aplicação do próprio método. Nessa metodologia, os pesquisadores e os participantes representativos da situação ou do problema estão envolvidos de modo cooperativo ou participativo". No artigo 14 também é possível inferir que houve a participação dos sujeitos, apesar de estes não estarem claramente definidos, como pode ser percebido na seguinte frase: "a metodologia adotada neste estudo foi a pesquisaação participante, em que todos os atores ligados à cadeia do trigo da Cooperativa Agroindustrial em estudo, situada na região centro-sul do Estado do Paraná, participaram intensamente das discussões que culminaram com a elaboração dos modelos."

Os autores do artigo 10 justificam o uso da PA devido ao processo de intervenção, afirmando que "esse método não se limita a apenas descrever uma situação, ele pretende, sim, em certos casos, desencadear mudanças no seio da coletividade implicada". Nos demais artigos não está claro o porquê usou a PA. No entanto destaca-se o artigo 12, o qual descreve claramente o método, todas as fases, baseados em Coughlan e Coghlan (2002), para os quais o ciclo de condução da PA se dá pelos seguintes passos: coleta de dados; feedback dos dados; análise dos dados; planejamento da 
ação; implementação da ação; avaliação. Neste artigo, todas essas etapas estão claramente identificadas. A descrição do método mereceu um capítulo específico, ricamente descrito, sempre relacionando com as ações que foram efetivamente realizadas no estudo. Os autores apresentam os principais resultados que a pesquisa gerou, após a implementação das ações definidas no decorrer no estudo. No final da conclusão, no entanto, os autores comentam sobre a necessidade de busca constante de rigor metodológico, citando que "uma das maiores ameaças ao rigor na pesquisa ação é a falta de imparcialidade do pesquisador na intervenção realizada. Esta foi uma preocupação constante na condução do trabalho e difícil de ser contornada, por meio da busca constante de autodisciplina, para não permitir que a profundidade de intervenção". Mas como ser imparcial em uma pesquisa-ação? A imparcialidade não é uma característica da PA, pelo contrário, busca-se a participação/intervenção tanto no pesquisador como pesquisados, conforme afirmação de Barbiei (2007, p. 14) quando diz que "a pesquisa-ação obriga o pesquisador de implicarse [...] não se trabalha sobre os outros, mas sempre com os outros". Cita-se ainda Thiollent (2003, p. 15) ao afirmar que "para que não haja ambiguidade, uma pesquisa pode ser qualificada de pesquisa-ação quando houver realmente uma ação por parte das pessoas ou grupos implicados no problema sob observação".

De acordo com Vergara (2005), a pesquisa-ação objetiva, simultaneamente, intervenção, elaboração de conhecimento e seu desenvolvimento. Já, segundo Novaes e Gil (2009), a PA tem características situacionais, pois procura diagnosticar um problema específico em uma situação específica, visando alcançar algum resultado prático àquela situação. No caso dos artigos internacionais verifica-se que as palavras "participação" e "colaboração" foram utilizadas para justificar o uso da pesquisa-ação em tais estudos. Destaca-se o artigo 7, no qual os autores citam que se buscou nesta colaboração a visão das diferentes partes interessadas a partir de um trabalho realizado em conjunto, destacando que, central para o sucesso da pesquisa foi o fato de que o conhecimento científico pode ser integrado com o conhecimento indígena, os agricultores podem colaborar com cientistas e funcionários do governo, correspondendo a uma integração interdisciplinar, pois as diferentes percepções dos agricultores e pesquisadores, assim como os diferentes conhecimentos e habilidades podem ser complementares, propiciando melhores resultados.

Para avaliar o enfoque de utilização da PA nas pesquisas em administração, deve-se considerar a motivação do pesquisador para realização do estudo, como apontado por McKay e Marshall (2007), ao salientarem que no caso do comprometimento com a pesquisa e produção do conhecimento, o que define o tema e o problema de pesquisa é o interesse do investigador, enquanto no caso da consultoria o problema de pesquisa refere-se a um problema organizacional para o qual se aplica a pesquisaação, visando resolvê-lo.

Com relação à motivação dos pesquisadores para realização dos estudos, tem-se: no artigo 1 os autores buscaram uma pequena empresa que concordasse em envolver-se ativamente na pesquisa, com foco na melhoria da gestão de custos e resultados econômicos. Neste caso, pode-se inferir que a motivação para a pesquisa parte dos pesquisadores. No artigo 4 os autores descrevem que "o projeto foi escolhido como um projeto prioritário para a área de operações com a pretensão de atuar na melhoria da qualidade do serviço prestado no caixa por meio da redução do tempo de espera do cliente na fila". Verifica-se, neste caso, clara motivação da empresa na melhoria de seu processo. No artigo 9 os autores descrevem que trata-se de atender os objetivos da federação das industrias. No artigo 10 está claramente evidenciada a necessidade de resolver um problema da organização "diante da necessidade da organização e das contribuições oferecidas pelo modelo em estudo...". 
No artigo 14 os autores descrevem que "atualmente os gestores das unidades de negócio da cooperativa agroindustrial em estudo [...], não possuem um sistema que demonstre os impactos desses investimentos na rentabilidade dos cooperados. Pela falta de um sistema de gestão [...] foi desenvolvido um modelo conceitual [...]", evidenciando que visa atender a um problema da organização, da mesma forma que no artigo 15 , o qual descreve que "na ocasião da pesquisa, as empresas haviam decidido implantar o plano de saúde para os funcionários e dependentes, mas enfrentavam alguns desafios [...]. Esses fatores contribuíram para a viabilidade da intervenção por meio da pesquisa-ação." No artigo 16 a "discussão em grupo para identificação da problemática: no caso estudado neste relato técnico, esta foi feita em conjunto com a organização". Nos demais casos não é possível identificar se a motivação para realização do estudo parte do pesquisador ou da organização na qual a pesquisa foi realizada.

Já no caso dos artigos internacionais, apesar de os artigos 1, 3 e 6 focarem a melhoria de processos, sendo gestão da inovação, formação de consultores e gestão estratégica, respectivamente, nos demais artigos, diferentemente do que se vê nos estudos nacionais analisados, há um viés para a melhoria das condições sociais dos sujeitos participantes da pesquisa. No caso do artigo 2 os autores comentam sobre a possibilidade de melhoria da condição de vida dos agricultores, a partir da introdução de um software que pode auxiliar na gestão das propriedades. Destaca-se, no entanto, que os autores se colocam como pesquisadores que visam "ajudar" os sujeitos, mesmo que estes tenham participado cooperativamente da pesquisa. No artigo os autores claramente destacam que se trata de uma pesquisa que visa a mudança social da comunidade rural na qual o estudo foi desenvolvido. Citam trechos das entrevistas realizadas com os agricultores e descrevem momentos, como o processo de avaliação, que ocorreu através de reuniões de grupo, além de entrevistas semiestruturadas. Evidenciou-se a clara ideia das mudanças sociais almejadas. Este é o único, entre todos os avaliados, que apresenta uma posição epistemológica relacionada a visão de Thiollent (1985, p. 14) para o qual a pesquisaação visa "alcançar realizações, ações efetivas, transformações ou mudanças no campo social". O artigo 5 comenta ter usado a pesquisa-ação, mas não esclarece em momento algum o porquê e muito menos como a utilizou.

A partir da análise dos fatores motivadores para realização das pesquisas e do por que utilizar a PA é possível concluir que, quando aplicada na administração, com base nos artigos nacionais selecionados e em parte dos internacionais, a PA objetivou resolver problemas das organizações. Pode-se inferir, neste sentido, que a PA aplicada na Administração, a partir da leitura desses artigos selecionados, aproxima-se dos conceitos Park (1999) e Martins (2006), para os quais, no âmbito das organizações, a pesquisa-ação pode ser vista como uma proposta de pesquisa mais aberta, com características de diagnóstico e consultoria e a motivação para realizá-las decorre da necessidade de melhorar o funcionamento da organização, visando assegurar a sua sobrevivência ou sua rentabilidade. No entanto, destacam-se os artigos internacionais 2, 4 e 7 , nos quais se percebe claramente o interesse em melhorar as condições de vida dos sujeitos envolvidos na pesquisa.

\section{Considerações Finais}

Este estudo teve por objetivo analisar o enfoque de aplicação da pesquisa-ação nas pesquisas em Administração, no cenário nacional e internacional, a partir das bases de dados e periódicos indexados a Capes. Para atender esse objetivo, utilizaram-se como parâmetro as características da pesquisaação evidenciadas por autores como Thiollent (1985, 2003, 2005), Tripp (2005), Vergara (2005) e Barbier (2007), para os quais a PA ocorre quando há participação ativa dos pesquisadores e pesquisados, visando intervenção, mudança. Cita- 
se ainda Thiollent (2003) para o qual a atuação do pesquisador não deve ser restrita a elaboração de um plano, mas sim na realização de ações efetivas, na transformação.

A partir da análise dos artigos é possível concluir que a maioria diz ter usado a PA, no entanto não é possível evidenciar suas características no estudo, exceto no artigo 12, no qual a PA está claramente descrita e é possível evidenciar suas características em todas as fases do estudo. Em pelo menos 6 artigos é possível questionar se a PA foi realmente empregada, pois entende-se que tais estudos são relatos de experiências de mudanças ou descrição de propostas, sem apresentar claramente as características básicas da PA.

Neste sentido, destaca-se a afirmação de De Sordi e Meireles (2010), para o quais a pesquisa em desenvolvimento deve trazer ação e almejar transformação do ambiente pesquisado; os pesquisadores estão envoltos, trazem o processo de mudança para entidade pesquisada, agindo no ambiente organizacional, seja como consultores, funcionários, colaboradores, fornecedores ou clientes.

Nos artigos pesquisados predomina a utilização da PA na abordagem de Park (1999), para o qual o enfoque de aplicação da PA em organizações decorre da necessidade de melhorar o funcionamento da organização, assim como para Martins (2006, p. 47-48), para o qual, no âmbito das organizações, a pesquisa-ação pode ser vista como "uma proposta de pesquisa mais aberta, com características de diagnóstico e consultoria para clarear uma situação complexa e encaminhar possíveis ações [...]”.

Salienta-se ainda que a busca pela superação da necessidade de distanciamento dos fenômenos é crescente nos estudos nas ciências sociais, conforme evidenciado por Novaes e Gil (2009), para os quais se verifica uma ênfase cada vez maior no campo da administração em pesquisas de cunho interpretativista, em que a ênfase está não na procura da objetividade, mas na maneira como os sujeitos de pesquisa interpretam a realidade que vivenciam. No entanto há uma grande dificuldade por parte dos pesquisadores em desvencilhar-se da abordagem dominante, o positivismo, o qual idealiza estudos empíricos, quantitativos, nos quais não há interferência por parte do pesquisador.

De acordo com Vergara e Peci (2003), a lógica positivista é predominante em pesquisas na área de Administração, tanto no cenário nacional como internacional. Devido as suas características, a pesquisa-ação pode possibilitar a descrição de situações concretas de coletividade e à intervenção dos sujeitos, orientada em função da deliberação de problemas ou de objetivos de transformação, conforme evidenciado por Thiollent (2003), podendo gerar uma inovação epistemológica nos métodos aplicados às pesquisas na Administração, pois se posiciona como uma corrente de princípios metodológicos de natureza argumentativa, na qual há interações entre pesquisador e pesquisado, opondo-se a ideia de não interferência das técnicas tradicionais (BARBIER, 2007; THIOLLENT, 2003), suportadas pelo paradigma dominante. Mas, como pode ser evidenciado nos resultados desse estudo, há um longo caminho pela frente.

Por fim, destacam-se alguns questionamentos de Thiollent (2003) sobre a aplicação da PA nas organizações: a quem a PA deve servir? Aos empresários e gestores? Aos empregados? Aos clientes? Aos acadêmicos? Os resultados deste estudo indicam que, nos trabalhos analisados, há indícios de que a PA tenha sido utilizada visando interesses organizacionais, dos empresários, prevalecendo sobre os empregados ou a comunidade. $\mathrm{Na}$ visão dos autores, a pesquisa-ação, quando aplicada na Administração, deve ter como objetivo evidenciar processos pelos quais os participantes coletivamente fazem análises críticas sobre a natureza de suas práticas, seus entendimentos e contextos em que praticam, a fim de enfrentar e superar a irracionalidade, injustiça, alienação e sofrimento nesses cenários e em relação às consequências de suas práticas nessas configurações. Entende- 
se que a pesquisa-ação é um método de pesquisa qualitativa, a qual visa descrever situações concretas de coletividade, nas quais a intervenção dos sujeitos é orientada em função da deliberação de problemas ou de objetivos de transformações, abrindo novos caminhos para a investigação social, em particular, na área organizacional, visando promover mudanças no ambiente pesquisado.

\section{Referências}

AUDET, Michel; DÉRY, R. La science réfléchie: quelques empreintes de l'épistémologie des sciences de l'administration. Anthropologie et Sociétés, Quebec, v. 20, n. 1, p. 103-123, 1996.

BARBIER, R. A pesquisa-ação. Brasília: Liber Livro, 2007.

BRANDÃO, C. R.; STECK, D. Participar-pesquisar. In: BRANDÃO, C. R. (Org.). Repensando a pesquisa participante. São Paulo: Brasiliense, 1999. p. 7-14.

BURRELL, G.; MORGAN, G. In search of a framework. Assumptions about the nature of social science. Assumptions about the nature of society. In: BURREL, G.; MORGAN, G . Sociological paradigms and organizational analysis. Burlington: Ashgale Publishing Company, 1979. Part 1, p. 1-16.

CALDAS, M. P.; FACHIN, R. Paradigma funcionalista: desenvolvimento de teorias e institucionalismo nos anos 1980 e 1990. Revista de Administração de Empresas, São Paulo, v. 45, n. 2, p. 46-51, abr./jun. 2005.

CAMPOS, A. M. Contribuição para o resgate da relevância do conhecimento para a administração. Physis: Revista de Saúde Coletiva, Rio de Janeiro, v. 7, n. 2, p. 105-127, dez. 1997.

CHEVALLIER J.; LOSCHAK, D. A ciência administrativa. Lisboa: Publicações Europa-América, 1982.

CRESWELL, J. Projeto de pesquisa: métodos qualitativo, quantitativo e misto. 2. ed. Porto Alegre: Bookman, 2007.

DE SORDI, J. O.; MEIRELES, M. Análise da estratégia de pesquisa declarada como pesquisa-ação por pesquisadores brasileiros na área de administração. eGesta: Revista Eletrônica de Gestão de Negócios, v. 6, n. 1, p. 1-20, jan./mar. 2010.

GAJARDO, M. Pesquisa participante na América Latina. São Paulo: Brasiliense, 1986.
GARCIA, F. C.; BRONZO, M. As bases epistemológicas do pensamento administrativo convencional e a crítica à teoria das organizações. In: ENCONTRO DA DIVISÃO DE ESTUDOS ORGANIZACIONAIS DA ANPAD EnEO, 1., 2000, Curitiba. Anais... Curitiba: ANPAD, 2000. p. 1-16.

COUGHLAN, P.; COGHLAN, D. Action research for operations management. International Journal of Operations \& Production Management, Bingley, v. 22, n. 2, p. 220-240, 2002.

GREENWOOD, D. J.; LEVIN, M. Reconstruindo as relações entre as universidades e a sociedade por meio da pesquisa-ação. In: DENZIN, N. K.; LINCOLN, Y. S. O planejamento da pesquisa qualitativa: teorias e abordagens. 2. ed. Porto Alegre: Artmed. 2006. Cap. 3, p. $92-113$.

HAIR JUNIOR, J. F. Fundamentos de métodos de pesquisa em administração. Tradução de Lene Belon Ribeiro. Porto Alegre: Bookman, 2005.

KEMMIS, S., MCTAGGART, R. Participatory action research. In: DENZIN, N. K.; LINCOLN, Y. S.(Ed.). Handbook of qualitative research. Thousand Oaks: SAGE, 2000. p. 567-605.

LE BOTERF, G. Pesquisa participante: propostas e reflexões metodológicas. In: BRANDÃO, C. R. (Org.). Repensando a pesquisa participante. São Paulo: Brasiliense, 1984. p. 51-81.

LEWIN, K. Pesquisa de ação e problemas de minoria. In: LEWIN, K. Problemas de dinâmica de grupo. São Paulo: Cultrix, 1970. p. 215-230.

MARTINS, G. Estudo de caso: uma estratégia de pesquisa. São Paulo: Atlas, 2006.

MCKAY, J.; MARSHALL, P. Driven by two masters, serving both: the interplay of problem solving and research in information systems action research projects. In: KOCK, N. Information systems action research: an applied view of emerging concepts and methods. New York: Springer, 2007. p. 131-158.

MENELAU, S., SANTOS, P. M. F.; CASTRO, B. G. A. Duas Senhoras, uma decisão: pesquisa sem ação ou pesquisa-ação na área de administração? In: ENCONTRO DA ANPAD, 35., Rio de Janeiro, 2011. Anais... Rio de Janeiro: ANPAD, 2011. p. 1-17.

MERRIAN, S. B. Qualitative research and case study applications in education. San Francisco: Jossey-Bass Publishers, 1998.

NEVES, J. L. Pesquisa qualitativa: características, usos e possibilidades. Cadernos de Pesquisas em Administração, São Paulo, v. 1, n. 3, p. 1-5, 1996. 
NOVAES, M. B. C.; GIL, A. C. A pesquisa-ação participante como estratégia metodológica para o estudo do empreendedorismo social em administração de empresas. RAM: Revista de Administração Mackenzie, São Paulo, v. 10, n. 1, jan./fev. 2009.

OLIVEIRA, M. M. Como fazer pesquisa qualitativa. 3. ed. Petrópolis: Vozes, 2007.

PARK, P. People, knowledge, and change in participatory research. Management Learning, Thousand Oaks, v. 30, n. 2, p. 141-157, 1999.

SERVA, M. O fato organizacional como fato social total. Revista de Administração Pública, Rio de Janeiro, v. 35, n. 3, p. 131-152, 2001.

SILVA, M. O. S. Refletindo a pesquisa participante. São Paulo: Cortez, 1991.

STRINGER, E. T. Action research: a handbook for practitioners. Thousand Oaks: Sage, 1996.

THIOLLENT, M. Metodologia da pesquisa-ação. 12. ed. São Paulo: Cortez, 2003.
. Metodologia da pesquisa-ação. São Paulo: Cortez, 1985.

$\overline{\text { Atlas, } 1997 .}$

Pesquisa-ação nas organizações. São Paulo:

TRIPP, D. Pesquisa-ação: uma introdução metodológica.

Educação e Pesquisa, São Paulo, v. 31, n. 3, p. 443-466, set./dez. 2005.

VERGARA, S.C. Métodos de pesquisa em administração. São Paulo: Atlas, 2005.

VERGARA, S. C.; CALDAS, M. P. Paradigma Interpretacionista: a busca da superação do objetivismo funcionalista nos anos 1980 e 1990. Revista de Administração de Empresas, São Paulo, v. 45, n. 4, p. 66-71, out./dez. 2005.

VERGARA, S. C.; PECI, A. Escolhas metodológicas em estudos organizacionais. Organizações \& Sociedade, Salvador, v. 10, n. 27, 2003. 